\title{
Entrepreneurial Marketing and Change Readiness
}

\author{
Jehiel Zif $^{1}$ \\ ${ }^{1}$ Department of Business Administration, Faculty of Management, Tel-Aviv University, Tel Aviv, Israel \\ Correspondence: Jehiel Zif, Associate Professor of Business Administration, Faculty of Management, Tel-Aviv \\ University, Tel Aviv, Israel.
}

Received: January 11, 2019

Accepted: February 19, 2019

Online Published: February 24, 2019

doi:10.5430/jms.v10n1p38

URL: https://doi.org/10.5430/jms.v10n1p38

\begin{abstract}
The paper outlines the critical rational of change readiness for entrepreneurial ventures. It is very difficult for innovative startups to assess correctly customers' response prior to actual entry. The probability of success increases when the venture adapts quickly to the feedback derived from users.

It is proposed that a proper and timely adaptation can be directed by applying systematic elements of change readiness. These elements are discussed with special attention to the unique characteristics of information gathering and interpretation in the case of new innovative products.
\end{abstract}

Keywords: entrepreneurial venture, entrepreneurial marketing, startup, change, readiness, innovation, entrepreneurship

\section{Introduction}

This paper explores the concepts of inertia and change from the point of view of entrepreneurial marketing. The paper builds on previously published papers by the author of this study (Zif 2016, 2010).

Change readiness has been largely discussed in the Organizational Behavior literature (Chonko et al. 2002; Eby et al. 2000; Gigliotti 2018, Jones et al 2005, Rafferty et al 2012, Weiner 2009). Most studies have associated change readiness with flexibility, and noted its importance for achieving a strategic advantage in an increasingly turbulent business environment. Relatively few studies have concentrated directly on the role of change readiness in entrepreneurial situations. Some studies have argued that institutional flexibility enhances entrepreneurship (Eesley, Roberts, Tian and Yang 2014). Other studies have tried to measure directly the relationship between Strategic Flexibility, Entrepreneurial Orientation and Performance (Yu, 2012). The need for flexibility by entrepreneurs has been suggested in commercial publications (Rao 2013). It has also been strongly advocated as a need to reverse ineffective strategic decisions by all executives (Shimizu and Hitt 2004).

In this paper, change readiness is viewed as a multidimensional construct that reflects the firm's competencies to do three things in order to adapt timely and properly to marketing feedback that follows entrepreneurial entry: trigger identification based on information gathering and interpretation; gearing up to take action (preparation); and action response.

The paper has four parts:

1. Unique elements of entrepreneurial marketing

2. Dealing with entrepreneurial marketing uncertainty

3. Change readiness for entrepreneurial marketing

4. Conclusions

\section{Unique Elements of Entrepreneurial Marketing}

What are the unique elements of entrepreneurial marketing? We can identify four common areas: 1. management team, 2. available resources, 3 . strategic objectives and 4 . uncertainty.

1. In most start-up companies there is a limited team of experienced managers. At the early stages of a new venture there is rarely a justification, or the means, to hire experienced managers for all key areas. Most innovative technological ventures are naturally started by people with a technological orientation and usually limited marketing 
experience and knowledge. As the business develops successfully, with more funding and clearer opportunities, recruiting of additional managers usually takes place.

2. A related issue for most entrepreneurial ventures at early stages is the need to raise funds. In most cases the business has to function for a period of time with limited resources. The limitation of resources and the entrepreneurs' backgrounds contribute to the concentration of early efforts on product development issues.

3. The strategic objectives of startup companies is usually quite broad and demanding: They need to complete product development, they need to raise money, they need to find and develop customers and they need to recruit additional committed team members for their activities.

4. Innovative entrepreneurship is a deviation from established patterns and is therefore difficult, if not impossible, to predict the outcome. As a consequence, a key unique element of entrepreneurial marketing is the high level of uncertainty in comparison with established businesses

The concept of marketing success with new products has different facets and the probability of failure varies by industry, by the nature of the product, by the strategy employed and by the business environment. But no matter how success is measured, the failure rate is quite high, particularly for startups. The high risk can be attributed to some of the following factors:

Uncertainty of product acceptance by customers

Uncertainty of product performance in use

Uncertainty of choosing the right customer segment

Uncertainty of achieving the required distribution

Unanticipated competitive response

Uncertainty of proper pricing for acceptance and repeat purchase

Inexperienced and technically oriented managers can easily err in interpreting what is going on at the early stages of marketing. Common mistakes include making projections based on trial data, with no repurchase data, and

confusing sales to early adopters with more stable sales to the early and late majority.

\section{Dealing With Entrepreneurial Marketing Uncertainty}

In dealing with uncertainty, we can identify four different approached to launch startups (Eizenmann, Ries and Dillard 2013):

1. A visionary approach, bypassing customer feedback and demand validation, relying on entrepreneurial vision. This approach is common in very innovative technology-oriented ventures. The assumption is that there is a very clear and established customer need, or that customers are unable to provide reliable feedback at the early stages of the venture.

2. A stage-gate approach which divides product development and marketing into stages that are completed one by one. In order to minimize faiure, each new stage in the process requires a review and approval, before the next stage is undertaken,. The approach is more common in established companies, with prior market experience, where the assumption is that the risk of failure can be reduced by careful study and review prior to launch. Two weaknesses of this approach for entrepreneurial ventures: 1. It is a cumbersome and slow process and 2. Many innovative products and services cannot get reliable feedback of future adoption prior to actual trial in the market place.

3. The lean startup approach recommends setting up a comprehensive list of business model hypotheses to be tested one by one by following a small set of market activities that can prove or disprove each hypothesis. As a result the approach is committing full scale resources only after adaptations that are based on the testing conclusions.

4. "Just Do It" is an improvisational approach which recommends an early product introduction with an intention to adapt the product and marketing model based on feedback from customers and distributers, after some real life experience.

There is tension between the need to sell a big vision to get investors' commitment and the slow and somewhat expensive process of validating many hypotheses of the lean start up approach, or accumulating customers' feedback by the improvisational approach. Additional concerns include an early exposure of an innovative idea to competition and the risk to reputation as a result of unsuccessful entry. In some industries, or product categories, there is also a limited ability to carry out proper testing without a full introduction of the complete product. 
In view of the above constrains, a common launching approach is frequently based on a big vision and a clearly defined product and marketing plan that was required for funding and team support. The problem, however, is that very few entrepreneurial business plans and forecasts survive the contact with customers. Startups "that ultimately succeed go quickly from failure to failure, all the while adapting, iterating on, and improving their initial ideas as they continually learn from customers" (Blank 2013).

Inertia has a strong influence on our life and on our decision making. While there is a need, in highly uncertain situations, to learn quickly from experience and modify the original plan, there is also a considered value to persist with the original plan in spite of difficulties.

\section{Change Readiness for Entrepreneurial Marketing}

As a result of the highly uncertain prospects of most innovative startups, it is essential to develop an organizational capability that can be called change readiness. A schematic model of Change Readiness (CR) is proposed in Figure 1.

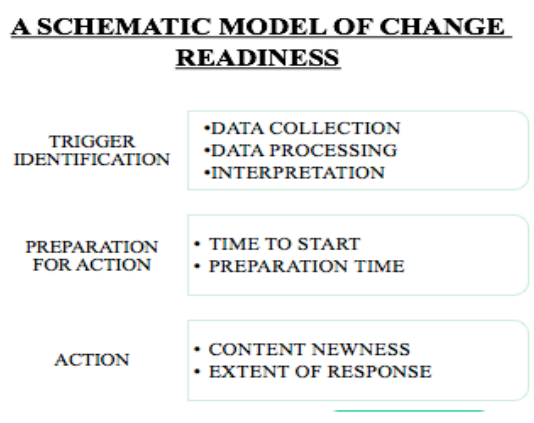

Figure 1

The first step in the readiness to cope with new conditions can be called trigger identification. First is the need to properly monitor customers' response, competitive developments and environmental realities by collecting relevant information. The costs of information gathering and experimentation in software, and in information technology businesses, can be quite low, and in these ventures one can get relatively quick feedback. Some of the information could be the direct outcome of experimental moves by the startup itself. For example, the startup might decide to test a specific promotion to find out if the expense is justified, by evaluating the number and quality of responses. In some cases however, the simple measurement of actual sales can be misleading. For example, in the early stages of a new frequently purchased consumer good most of the sales are trial sales. Unless the startup collects information about repeat purchase and confirms customers' satisfaction with the initial purchase, the early sales figures may not be reliable for forecasting.

Another common case of insufficient data collection is the dependence on sales data to a major intermediary such as a wholesaler, a chain store, or a distributor. A nice contract may not be sustainable without evidence that final consumers use the products. An early enthusiasm with a large contract to an intermediary can sometimes ends with a big disappointment, when sales to final consumers are lacking. This has been my experience as the author of this paper. I have raised venture capital for a company to develop simulation games, based on a commitment by a major publisher, to publish and distribute the games. Since we had signed contracts, with nice advance payments against future royalties, most of the work in the first two years concentrated on product development of twelve simulation games. We did not devote time to study the acceptance of these games by potential users. We relied on the publisher as an experienced marketer to do the work with the users. This turned out to be a big mistake. In retrospect it would have been much better to develop fewer games and carry out a deep study of the first few products in use.

Another possible trap is listening to the wrong people, particularly at the early stages (Godin 2019). When the venture is focused on a specific narrow segment, feedback from people, who are part of the majority, but don't belong to the target segment, could be misleading. 
There is also a difference between behavioral information, which is relatively easy to collect, and motivational information about the causes of behavior. When behavioral information is disappointing it is frequently essential to enquire further about the real explanation for customers' action. A good understanding of the reasons of disappointing sales can make a big difference in determining the needed action of response.

Second, the observed signals should be processed to separate meaningful developments from random noise. There is also a specific need to separate special causes from common causes. There is frequently a question whether a relevant development is a result of a special situation. For example are we learning about sales to a unique customer, a specific time period, or an exceptional distributer, or about a general issue with strategic implications?

The third step requires translation of the findings into a conclusion that some change is necessary, or desirable. Typical mistakes that managers make at this stage is denying a disappointing signal, or concluding that there is no problem and no need for change. There is a strong inclination to delay necessary action when a marketing plan assumption of a potential market is not materializing. Being aware of the personal and organizational tendency to reject signals with threatening consequences could possibly help in making a more objective assessment.

In many cases, proper interpretation requires an information-based model in order to diagnose the developments and forecast what is likely to come. For example, is a disappointing level of sales a result of a poor product, insufficient promotion, wrong sales effort or an incorrect estimate of potential consumption? The implications for action are very different between the different causes of poor performance.

The second phase of change readiness is preparation for action. Recognizing a need, or an opportunity, is a necessary but insufficient condition for undertaking strategic change. The second variable, therefore, deals with the time it takes to respond. The time response variable, however, is not detached from the environment-monitoring variable: If the startup is slow in identifying a need for change then the time available for preparing action might be quite short before it is too late (Ansoff 1984). In similarity with a medical condition, an early identification of a need for change increases the likelihood of success with the action taken.

Preparation time is content-related, i.e., if a new development requires a major change of product or marketing approach, with a need to learn and apply new knowledge and skills, then a long preparation time is inevitable.

A frequent need to make changes is the necessity to divert attention and marketing efforts from the early adopters to the early majority. In many cases the customers' needs are different between the two groups and a timely change of focus is essential to keep the momentum going.

It has been argued that the speed, with which one moves from trigger identification to action, is the most critical component for successful strategic change. (Kotter, 2008)

The third dimension of change readiness is the action of response, or more specifically, the degree to which the response to the trigger is appropriate. Sometimes a minor change, or no action, is sufficient. In other cases, an incremental action, like doing more of the same, is the wrong response. In the uncertain environment of most startups, effective strategic change is highly associated with action innovations rather than an attempt to defend existing strategies. Confusing the need for transformational change with incremental moves is a typical mistake. Reactive activity, which reflects tactical flexibility, may be less effective for the long haul when major changes are necessary.

The trigger identification stage may also show that the entrepreneurial idea is not working and the best action is to terminate the project, rather than change some parameters. An organizational tolerance for failure is important, in order to optimize resources for the long term.

\section{Conclusion}

Most entrepreneurs are under conflicting pressures. On the one hand they need to show a commitment to carry out their new venture plan in the face of difficulties and challenges and on the other hand they need to be responsive to customers and adapt to their feedback. This dilemma is particularly critical for managing new innovative ventures because of the high uncertainty, which is evident in the high failure rate. There could be many reasons for entrepreneurial failure, but one publication argues that the "The worst mistake of all, however, is that most startup founders get stuck on their original idea and refuse to pivot." (Nicolas, 2018)

To increase the probability of success in entrepreneurial marketing the venture needs to develop certain capabilities which we call change readiness. These capabilities are: environmental trigger identification based on effective information gathering and interpretation, quick mobilization in preparing for change and boldness in selecting the proper content of response. The boldness is necessary in order to overcome inertia in getting stuck with the original 
idea and marketing plan. Effective information gathering, analysis and interpretation is essential in order to decide whether a change is necessary and in outlining the direction of change.

High performance on these variables has been shown, by an exploratory study of firms, to be correlated and a possible predictor of success in dealing with major threats and opportunities (Zif, 2016). Additional empirical research with entrepreneurial firms could be useful in validating and supporting the concepts outlined in this paper.

\section{References}

Aaker, D. A., \& Mascarenhas, B. (1984). The Need for Strategic Flexibility. Journal of Business Strategy, 5(2), 74-82. https://doi.org/10.1108/eb039060

Ansoff, H. I. (1984). Implanting Strategic Management. Prentice-Hall, New Jersey.

Blank, S. (2013). Why the Lean Start-up Changes Everything. Harvard Business Review. Retrieved from https://hbr.org/2013/05/why-the-lean-startup-changes-everything

Chonko, L. B., Jones, E., Robert, A. J., \& Dubinsky, A. J. (2002). The role of environmental turbulence, readiness for change, and salesperson learning in the success of salesforce change. Journal of Selling and Sales Management, 12(4), 227-45.

Cole, N. (2018, February 9). Why Do Most Startups Fail?.

Eby, L. T., Adams, D. M., Russell, J. E., \& Gabay, S. H. (2000). Perceptions of Organizational Readiness for Change: Factors Related to Employees' Reactions to the Implementation of Team-based Selling. Human Relations, 53, 419-42. https://doi.org/10.1177/0018726700533006

Eesley, C., Roberts, E. B., Tian, X., \& Yang, D. (2014). Institutional Flexibility and Entrepreneurship. Working paper, Stanford Center for International Development.

Eisenmann, T., Ries, E., \& Dillard, S. (2013). Hypothesis-Driven Entrepreneurship: The Lean startup. Harvard Business School Background Note 812-095.

Gigliotti, R., Vardaman, J., Marshall, D. R., \& Gonzales, K. (2018). The Role of Perceived Organizational Support in Individual Change Readiness. Journal of Change Management. https://doi.org/10.1080/14697017.2018.1459784

Godin, S. (2019). The Trap of Early Feedback. Retrieved from https://seths blog/2019/02/the-trap-of-early-feedback

Jones, R. A., Jimmieson, N. L., \& Griffiths, A. (2005, March). The Impact of Organizational Culture and Reshaping Capabilities on Change Implementation Success: the Mediating Role of readiness for Changes. Journal of Management Studies, 42(2), 361-86. https://doi.org/10.1111/j.1467-6486.2005.00500.x

Kerr, W. R., Nanda, R., \& Rhodes -Kropf, M. (2014). Entrepreneurship as Experimentation. Journal of Economic Perspectives, 28(3). https://doi.org/10.1257/jep.28.3.25

Kotter, J. P. (2008). A Sense of Urgency. Harvard Business Press, Boston. Retrieved from https://hbr.org/product/a-sense-of-urgency/10007-HBK-ENG

Rafferty, A. E., Jimmieson, N. L., \& Amenakis, A. A. (2012, September 5). Change Readiness; a Multilevel Review. Journal of Management.

Rao, D. (2013). Entrepreneurs need to be Flexible because Forecasts are Always Fallible, Lessons from Billion Dollars Entrepreneurs. Entrepreneurs.

Shimizu, K., \& Hitt, M. A. (2004). Strategic flexibility: Organizational preparedness to reverse ineffective strategic decisions. Academy of Management Executive, 18(4).

Timmor, Y., \& Zif, J. (2010). Change Readiness: An Alternative Conceptual and Empirical Examination. Euro Med Journal of Business, 5(2), 138-165. https://doi.org/10.1108/14502191011065482

Weiner, B. J. (2009). A Theory of Organizational Readiness for Change. Implementation Science, 4(67). https://doi.org/10.1186/1748-5908-4-67

Yu, F. (2012). Strategic Flexibility, Entrepreneurial Orientation and Firm Performance: Evidence from Small and Medium size Business (SMB) in China. African Journal of Business Management, 6(4), 1711-1720.

Zif, J. (2016, February). Patterns of Response to Global Threats and Opportunities. Journal of Management and Strategy. 